\title{
Insight into the oxidative desulfurization of high-sulfur petroleum coke under mild conditions: a journey of vanadium-substituted Dawson-type phosphotungstic acid
}

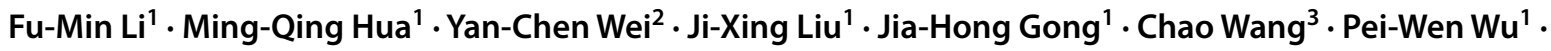 \\ Yan Huang ${ }^{1}$. Hua-Ming $\mathrm{Li}^{1} \cdot$ Wen-Shuai $\mathrm{Zhu}^{1}$
}

Received: 3 September 2020 / Accepted: 5 January 2021 / Published online: 12 February 2021

(c) The Author(s) 2021

\begin{abstract}
High-sulfur petroleum coke (HSPC), that is a by-product from slag oil in the coking process of refining, shows versatility values in practical applications and, however, concentrates the majority of organic sulfur. Herein, we design and construct a highly effective CTAB@HPA composites to be explored for the catalytic oxidative desulfurization of HSPC under mild conditions using hydrogen peroxide as the oxidant and 1-butyl-3-methylimidazole tetrafluoroborate ionic liquid as the extractant. The results demonstrate that the sulfur content of HSPC could be strikingly reduced from $4.46 \mathrm{wt} \%$ to $2.48 \mathrm{wt} \%$ under $60{ }^{\circ} \mathrm{C}$ and atmospheric pressure, and that the organic sulfur in HSPC is mainly oxidized to sulfoxide, sulfone and sulfate, which latter can be directly separated from petroleum coke. Moreover, the effect of reaction conditions on the desulfurization performance of HSPC as well as the catalytic oxidation reaction kinetic of HSPC desulfurization was systematically investigated. Furthermore, a mechanism for the oxidative desulfurization of HSPC over CTAB @ HPA catalysts was proposed. Therefore, this work provides new insight into how to construct active catalysts for the desulfurization of HSPC under mild conditions.
\end{abstract}

Keywords High-sulfur petroleum coke · Dawson-type phosphotungstic acid · Oxidative desulfurization · Mild conditions · Sulfate

\section{Introduction}

With the development of the automobile industry, the demand for fuel is ever-increasing. However, the sulfur-containing compounds in the oil seriously pollute the ecological environment (Zhu et al. 2016; Lu et al. 2018; Yao et al. 2018; Wang et al. 2020; Li et al. 2020, 2019b; Hao et al. 2019; Han et al. 2019; Liu et al. 2020b, 2020c). Petroleum coke,

Edited by Xiu-Qiu Peng

Ming-Qing Hua

huamq840710@163.com

Wen-Shuai Zhu

zhuws@ujs.edu.cn

1 School of Chemistry and Chemical Engineering, Jiangsu University, Zhenjiang 212013, China

2 School of Materials Science and Engineering, Jiangsu University, Zhenjiang 212013, China

3 School of the Environment and Safety Engineering, Jiangsu University, Zhenjiang 212013, China a by-product from the coking of slag oil in refining, shows versatile applications in the industry based on its quality. The low-sulfur petroleum coke ( $\mathrm{S}<3.0 \mathrm{wt} \%$ ) is mainly used to manufacture carbon products such as graphite electrodes (Wei et al. 2017), activated carbon (Choi et al. 2012), carbon fiber (Briceño et al. 2015), graphite (Wu et al. 2017). High-sulfur petroleum coke (HSPC, $\mathrm{S}>3.0 \mathrm{wt} \%$ ) is typically employed as fuel for heating or power, and it can only be classified as waste which causes environmental issues and needs to be handled with considerable cost (Chen and $\mathrm{Lu}$ 2007; Peng et al. 2019; Zhong et al. 2018b, 2019). Therefore, in order to adapt to the new requirements of energy conservation and environmental protection, developing an alternative method to reduce the sulfur content of HSPC is extremely desirable.

According to the composition of the crude oil and coking process, the type of sulfur in HSPC could be categorized into organic sulfur (>99.8\%) and inorganic sulfur (Zhong et al. 2018a), in which thiophene derivatives are the most popular organic sulfur and mainly attached to the aromatic carbon skeleton and the branch of paraffin on the surface of 
the aromatic ring (Zhao et al. 2018; Li et al. 2019a). Currently, the desulfurization methods for HSPC include the calcination method, vacuum calcination (Chen et al. 2017; Ishihara et al. 2005; Xiao et al. 2016), hot alkali calcination (Agarwal, Sharma 2011), hydrodesulfurization and catalytic oxidative desulfurization method (Ganiyu et al. 2017; Toledo-Antonio et al. 2017). Among them, catalytic oxidative desulfurization strategy has shown attracted extensive attention due to its low cost and high efficiency, and the highly efficient catalyst is recognized to be the crucial factor influencing the desulfurization performance of this process. Liu et al. (Liu et al. 2020a) used the $[\mathrm{Bmim}]_{3} \mathrm{PW}_{12} \mathrm{O}_{40}$ for the desulfurization of HSPC; however, this catalyst required more demanding reaction conditions. Therefore, it is imperative to find a catalyst that is efficient and can operate under mild conditions.

Polyoxometalates (POMs) are a type of polyacid compounds polycondensed by co-angled, co-edge (occasion coplanar) oxygenation in a unit of metal oxides (Jiang et al. 2018; Zhang et al. 2017). Heteropoly acid (HPA), a typical POMs composed of metal oxides and heteroatoms, which are strong inorganic acids possessing defined molecular structures has drawn much attention because of its excellent catalytic performance. Therefore, phosphotungstic acid has received much more attention because of their acidic and redox properties and environmental-friendly trait (Banisharif et al. 2017). According to the molecular cluster, HPA can be classified into Keggin type (Zhang et al. 2020), Dawson type (Long et al. 2010) and Anderson type (Chi et al. 2020; Zhang et al. 2017) et al. Te et al. (Te et al. 2001) have highlighted that heteropolyacids with Keggin structure can effectively activate hydrogen peroxide and oxidize dibenzothiophene to form corresponding sulfone species. Muñoz (Muñoz et al. 2017) found that molybdenum heteropolyacids with Anderson structure exhibit impressive catalytic activity for the abatement of $p$-phenylene sulfide. Albert et al. (Bertleff et al. 2017) proposed that $\mathrm{H}_{8} \mathrm{PV}_{5} \mathrm{Mo}_{7} \mathrm{O}_{40}$ in Dawson structure could catalytic oxidative thiophenes and thioether sulfur compounds into water-soluble sulfates and sulfonic acid compounds. Nevertheless, it was found that HPA was prone to loss of active components under the oxidizing atmosphere, which is extremely unfavorable for the removal of sulfides in practical utilization. Thus, it is highly desirable to develop a high efficiency and thermal stable HPA-based catalyst to be used for the catalytic oxidation desulfurization. Moreover, to date, the report related to HPA employed for catalytic oxidation desulfurization of HSPC has not been noted, and the corresponding reaction kinetics and mechanism for the process have never investigated yet.

In this contribution, we present a high efficiency Dawson-type HPA complexes (CTAB @ HPA) with high targeting effect by combining quaternary ammonium anions with locally positive Lewis acid organic cations, to be probed for the catalytic oxidation desulfurization of HSPC. The experimental results demonstrated that the highest yield of soluble sulfate was found in CTAB@HPA-5, which achieves the remarkable removal of sulfur content in HSPC from $4.46 \mathrm{wt} \%$ to $2.48 \mathrm{wt} \%$ under $60{ }^{\circ} \mathrm{C}$ and atmospheric pressure. Moreover, the effect of reaction conditions on the desulfurization performance of HSPC was also systematically investigated, and a mechanism for the oxidation desulfurization HSPC over CTAB @ HPA catalysts was proposed.

\section{Experimental section}

\subsection{Materials}

HSPC was purchased from Carbon Factory of Zhenjiang (China). 1-Butyl-3-methylimidazolium tetra-fluoroborate ([Bmim $\left.] \mathrm{BF}_{4}\right)$ was purchased from Chengjie Reagent Co., Ltd (China). Cetyltrimethylammonium bromide (CTAB), tetrabutylammonium chloride, sodium tungstate dihydrate, ammonium metavanadate, sodium phosphate, hydrochloric acid, sulfuric acid, anhydrous ethyl ether, acetonitrile, absolute ethanol, $30 \% \mathrm{H}_{2} \mathrm{O}_{2}$ were purchased from Sinopharm Reagent Co., Ltd (China).

\subsection{Characterization method}

All the applied characterizations for catalyst samples are listed in "Supporting Information."

\subsection{Preparation of catalyst}

$\mathrm{H}_{6+x} \mathrm{P}_{2} \mathrm{~W}_{18 x} \mathrm{~V}_{x} \mathrm{O}_{62}(x=1-6)$ (HPA- $x$ ) heteropolyacids were prepared according to the method reported in the literature (Banisharif et al. 2017). The typical preparation method for the representative $\mathrm{H}_{11} \mathrm{P}_{2} \mathrm{~V}_{5} \mathrm{~W}_{13} \mathrm{O}_{62}$ (HPA-5) is as follows: At room temperature, $0.05 \mathrm{~mol} \mathrm{NH}_{4} \mathrm{VO}_{3}$ and $0.02 \mathrm{~mol} \mathrm{Na}_{3} \mathrm{PO}_{4}$ were dissolved in $100 \mathrm{~mL}$ deionized water and then $0.01 \mathrm{~mol}$ $\mathrm{Na}_{2} \mathrm{WO}_{4}$ was added. Subsequently, the $\mathrm{pH}$ of the above solution was adjusted to 4.4 with $1 \mathrm{~mol} / \mathrm{L} \mathrm{H}_{2} \mathrm{SO}_{4}$. Then the solution was heated to $96{ }^{\circ} \mathrm{C}$ and refluxed for $8 \mathrm{~h}$. After the solution was cooled to room temperature, $150 \mathrm{~mL}$ of ether was added and the red oil phase was separated. Finally, HPA-5 was obtained by evaporating the ether at $200^{\circ} \mathrm{C}$. Other samples with different contents and treated temperature were prepared with the above similar method (Table S1).

CTAB@HPA-5 was synthesized as follows: $1 \mathrm{mmol}$ of the as-prepared HPA-5 was dissolved in $25 \mathrm{~mL}$ deionized water, and then the $\mathrm{pH}$ of the above solution was adjusted to 4.4 with $2 \mathrm{~mol} / \mathrm{L} \mathrm{HCl}$ solution. The obtained solution was denoted as A. Then $0.01 \mathrm{~mol}$ of CTAB was introduced into $40 \mathrm{~mL}$ of ethanol and marked as B. Subsequently, solution B was added dropwise into solution A under continuously stirring. Finally, 
CTAB@HPA-5 product was obtained after being continuously stirred, filtered and dried in an oven at $100{ }^{\circ} \mathrm{C}$ for $12 \mathrm{~h}$.

\subsection{Pretreatment process of HSPC}

The HSPC was first pretreated to increase the specific surface area of HSPC (Table S2), so that the HSPC can react with the oxidation group better, thus realizing deep desulfurization. The pretreatment process used tetrabutylammonium chloride and HSPC to work together. The specific operation had been reported in our previous paper (Liu et al. 2020a).

\subsection{Oxidative desulfurization process}

HSPC was oxidized and desulfurized in a 50-mL round-bottom flask. Firstly, $0.5 \mathrm{~g}$ of catalyst was added into the aforementioned round bottom flask. Then $5 \mathrm{~mL}$ of ionic liquid $[\mathrm{Bmim}] \mathrm{BF}_{4}$ was introduced, and the mixture was heated to $60{ }^{\circ} \mathrm{C}$. Finally, the pretreated petroleum coke and $\mathrm{H}_{2} \mathrm{O}_{2}(1 \mathrm{~mL})$ were added.

The residual sulfide concentration of petroleum coke at $t$ (h) was determined by microcoulometry (GLS-3000). The desulfurization rate of residual sulfide in petroleum coke is calculated by Eq. 1, where $\omega_{0}$ is the mass fraction of original petroleum coke sulfide and $\omega_{1}$ is the mass fraction of petroleum coke sulfide after the reaction. This calculation method is widely used in the field of catalytic oxidation desulfurization and is accepted by most researchers.

sulfur removal $(\%)=\left(1-\omega_{1} / \omega_{0}\right) \times 100$

\section{Results and discussion}

\subsection{Characteristics of catalyst samples}

The physicochemical properties of the as-constructed HPA- $x$ and CTAB@HPA- $x(x=1-6)$ were first characterized by FT-IR spectra (Fig. 1). It is noted that Dawson structure absorption band is observed at 700-1100 $\mathrm{cm}^{-1}$ (Dablemont et al. 2006). Among them, the band centered at $1100 \mathrm{~cm}^{-1}$ is attributed to $P=\mathrm{O}$ antisymmetric stretching vibration band. The band at $960 \mathrm{~cm}^{-1}$ is assigned to the antisymmetric stretching symmetric vibration peak of $\mathrm{W}, \mathrm{V}$ and terminal oxygen, and the band at $780 \mathrm{~cm}^{-1}$ is associated with heteropolyacid corresponding to the bridge bond vibration of W-O-W, V-O-V (Zhang et al. 2013; Li et al. 2015). It is noteworthy that the band at $1100 \mathrm{~cm}^{-1}$ is a splitting peak, which should be originated from the different distance between $\mathrm{P}$ and four coordinative oxygen in the tetrahedron of $\mathrm{PO}_{4}$. Besides, when the anion is separated by organic cation, the coupling between $\mathrm{W}=\mathrm{O}, \mathrm{V}=\mathrm{O}$ is eliminated. It is recognized that the larger the angle of the bridge key is, the higher the vibration frequency is. Therefore, the band at $780 \mathrm{~cm}^{-1}$ should be ascribed from the vibration of the bridge key with the same side oxygen in the six-element ring. Figure $1 \mathrm{~b}$ shows two bands at 1470 and $1640 \mathrm{~cm}^{-1}$, which are ascribed to $\mathrm{N}-\mathrm{H}$ bond deformation vibration and $\mathrm{C}=\mathrm{N}$ bond stretching vibration of CTAB, respectively (Yang et al. 2017). In addition, all samples show three Dawson structural characteristic bands in the range of $700-1200 \mathrm{~cm}^{-1}$ with slight deviations. The above results indicate that CTAB @HPA composites are successfully constructed by this facile strategy.

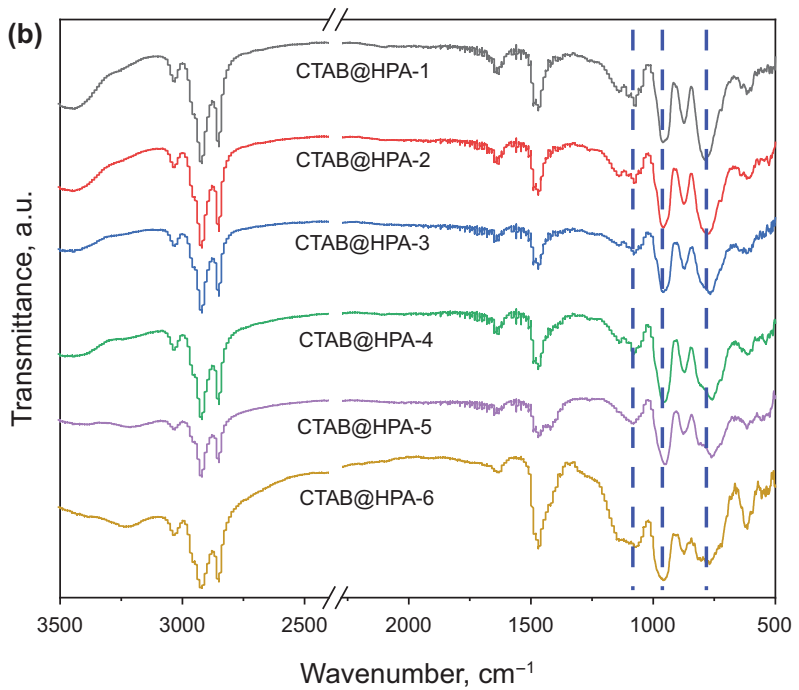

Wavenumber, $\mathrm{cm}^{-1}$

Fig. 1 FT-IR spectra of a HPA- $x(x=1-6), \mathbf{b}$ CTAB @HPA- $x(x=1-6)$

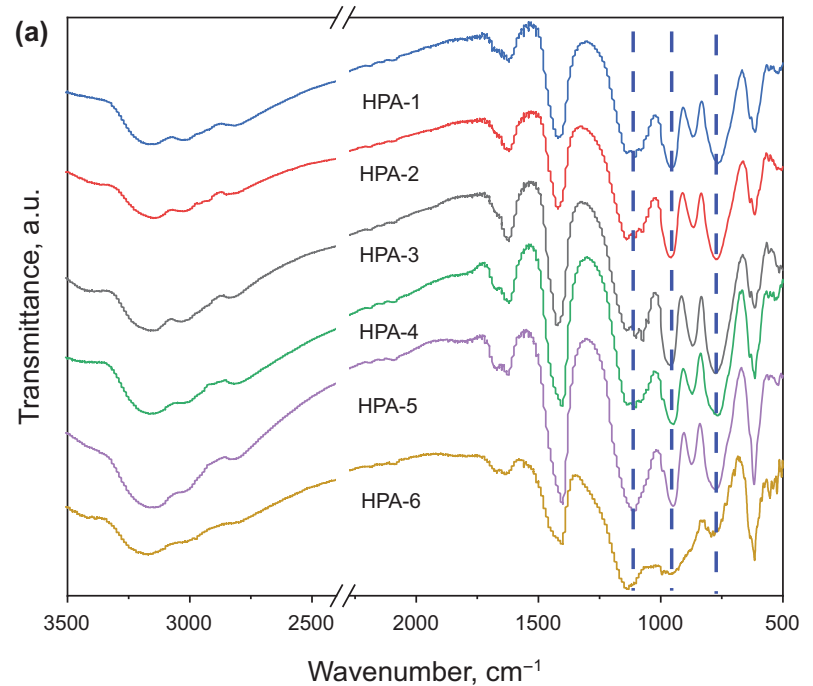


In order to confirm the composition of the as-prepared samples, we performed XRD analyses (Fig. 2). It can be seen from Fig. 2a that all the heteropoly acids exhibit similar XRD patterns in the region, of $2 \theta=5-40^{\circ}$ (Wang et al. 2016; Rohani et al. 2017; Gim et al. 2016). Figure 2b shows that the Dawson structures of CTAB @HPA- $x(x=1-6)$ were well retained after the introduction of CTAB compared with HPA- $x(x=1-6)$. Therefore, it could be deduced that the heteropoly acid anions with multiple negative charges should be surrounded by CTAB cations through electrostatic interactions, which should be favorable for the monodispersed heteropoly acids as a single cluster of charge compensation (Song et al. 2019).

The morphology and composition of the as-prepared HPA- $x$ and CTAB @HPA- $x$ were further investigated by SEM and EDS analyses, and the results are illustrated in Fig. 3. According to previous reports, used of $0.25 \mathrm{~mol} / \mathrm{L}$ CTAB solution could enhance the catalyst activity

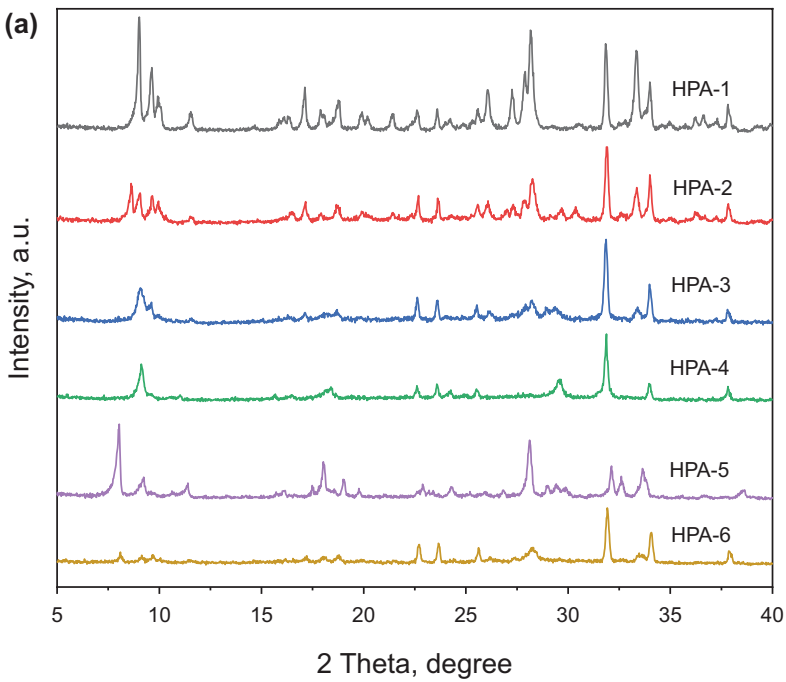

Fig. 2 XRD patterns of a HPA- $x(x=1-6), \mathbf{b}$ CTAB @HPA- $x(x=1-6)$
(Banisharif et al. 2017), while excessive addition of CTAB will cause agglomeration of the catalyst, thereby reducing the number of active sites of the catalyst, which in turn decrease the desulfurization activity. SEM results show that the representative HPA-5 presents the flake-like nanosheets, which are similar to snowflakes. The EDS analysis further confirms the composition of HPA-5. In addition, after the introduction of surfactant CTAB (Fig. 3c), CTAB @ HPA-5 displays an aggregated morphology with porous structure, which should be favorable for the expose of more active sites and the accessibility of actives to reactants, thereby benefiting the oxidative desulfurization performances of CTAB@ HPA catalysts.

To study the chemical state of the elements in POM, we carried out XPS analyses for HPA-5 and CTAB@HPA-5 (Fig. 4). As observed from Fig. 4a, the binding energy peaks of $\mathrm{C}, \mathrm{O}, \mathrm{P}, \mathrm{W}$ and $\mathrm{V}$ are detected in HPA-5 and CTAB @ HPA-5 samples, indicating the successful synthesis of (b)

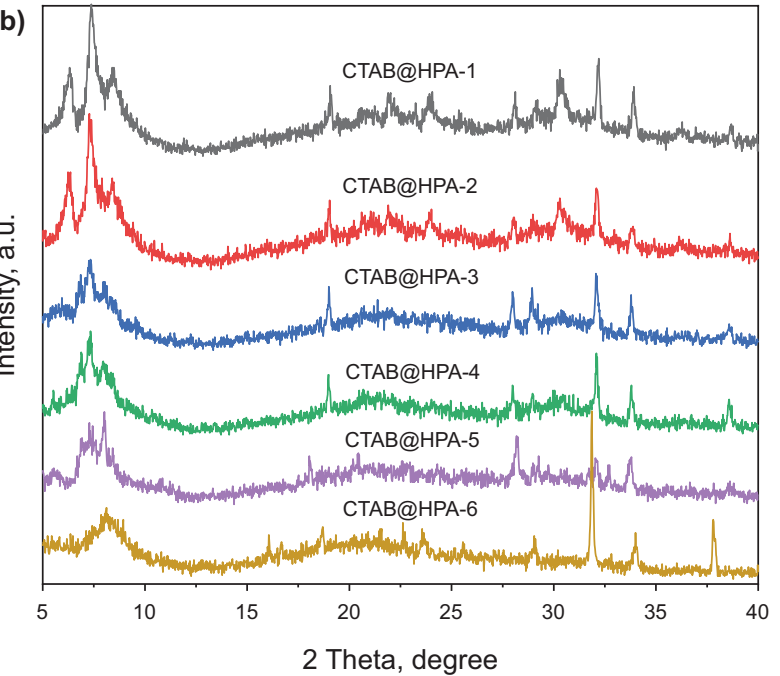

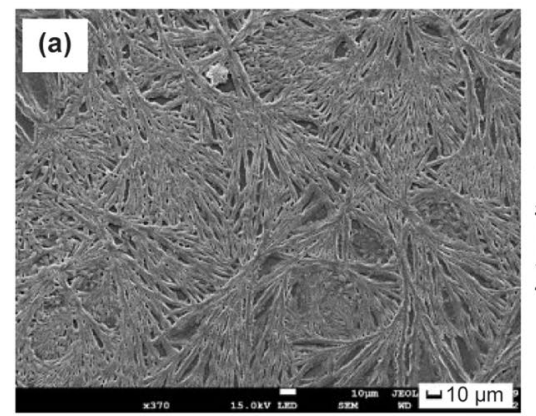
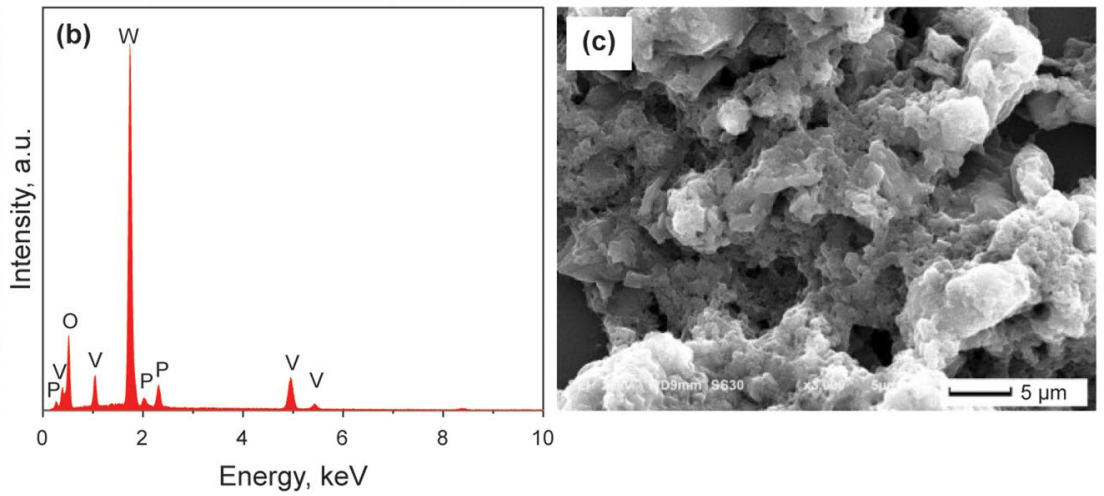

Fig. 3 SEM image of a HPA-5, b EDS analysis of HPA-5, c SEM images of CTAB@HPA-5 

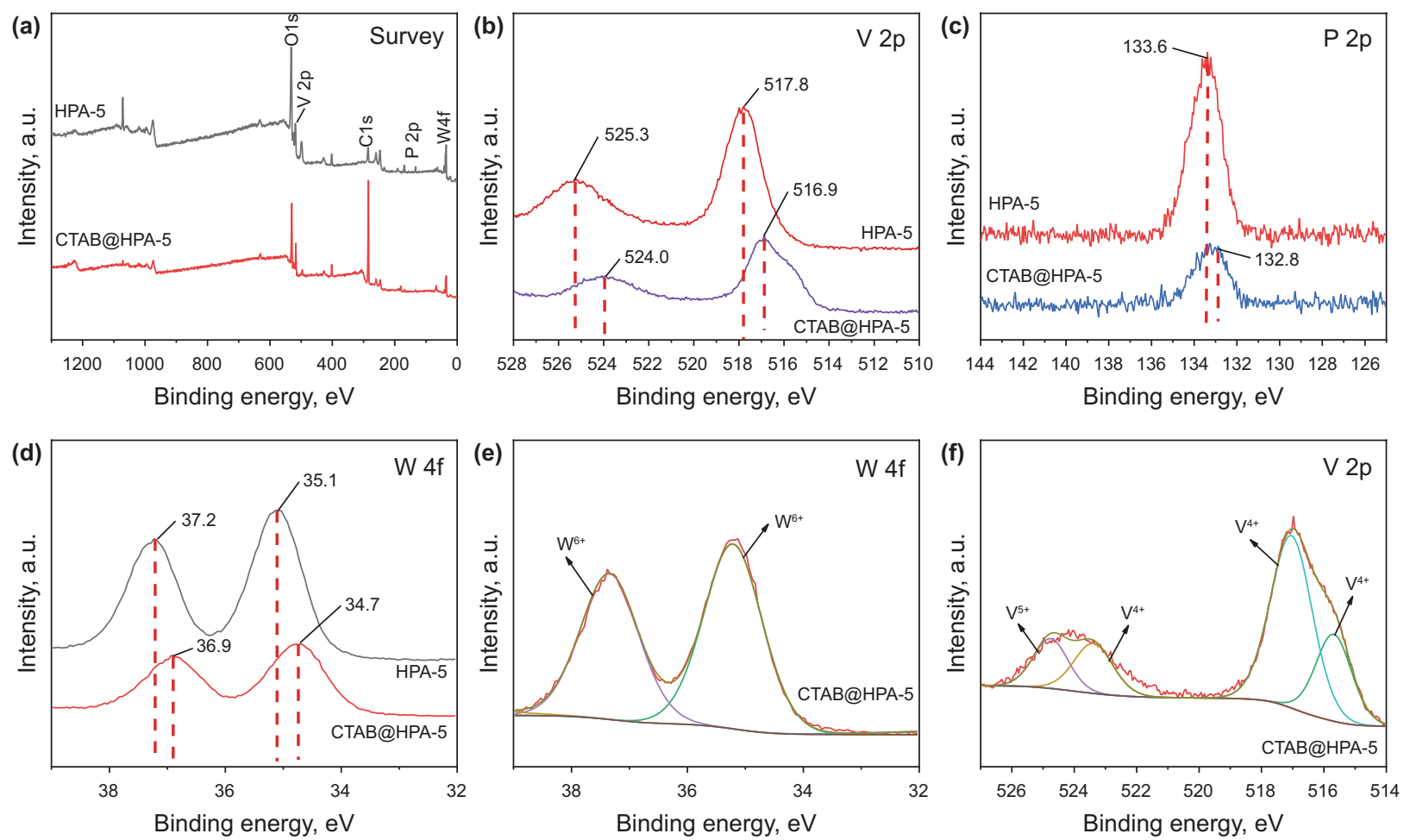

Fig. 4 XPS of HPA-5 and CTAB@HPA-5: a survey; b V 2p; c P 2p and d W 4f; peak deconvolutions for e W 4f; f V 2p of CTAB @ HPA-5

heteropolyacid and POM. Figure 4(b-d) results show that a red shift of the binding energy for $\mathrm{V} 2 \mathrm{p}, \mathrm{W}$ f and $\mathrm{P} 2 \mathrm{p}$ in CTAB@ HPA-5 was noted compared with that of HPA5. It reveals the presence of the electrons migration from CTAB cation to CTAB@HPA-5 anion and strong interaction between CTAB and HPA-5. That is to say, CTAB@HPA-5 is not just mixture but hybrid with close interaction between each other. Moreover, the results confirm that the element tungsten mainly exists as $\mathrm{W}^{6+}$ in POM (Fig. 4e) (Chen et al. 2020; Song et al. 2019), and that $\mathrm{V}^{5+}$ and $\mathrm{V}^{4+}$ oxidation states coexisted in POM (Fig. 4f).

\subsection{Catalytic oxidative desulfurization performance}

The oxidative desulfurization performances of the as-prepared HPA and CTAB@HPA for HSPC were investigated, and the results are summarized in Table 1 . It is noted that the desulfurization performances of HPA- $x$ gradually increase with the increase in vanadium content. It reaches the largest with $42.38 \%$ sulfur removal as the HPA-5. Further increasing the $\mathrm{V}$ content leads to a decrease in desulfurization performance. Moreover, when CTAB was introduced, the catalytic oxidative desulfurization activities of corresponding CTAB @HPA were further improved, and CTAB @HPA-5 gives the highest catalytic oxidative desulfurization activity among all these samples with $44.39 \%$ sulfur removal.
Table 1 Catalytic performance of samples in oxidative desulfurization reaction at $60{ }^{\circ} \mathrm{C}$

\begin{tabular}{llll}
\hline Entry & Samples & $\begin{array}{l}\text { Residual sulfur } \\
\text { content, wt\% }\end{array}$ & $\begin{array}{l}\text { Sulfur } \\
\text { removal, } \\
\%\end{array}$ \\
\hline 1 & HPA-1 & 3.75 & 15.92 \\
2 & HPA-2 & 3.42 & 23.32 \\
3 & HPA-3 & 3.27 & 26.68 \\
4 & HPA-4 & 3.01 & 32.51 \\
5 & HPA-5 & 2.57 & $\mathbf{4 2 . 3 8}$ \\
6 & HPA-6 & 3.33 & 25.34 \\
7 & CTAB @ HPA-5 & 2.48 & $\mathbf{4 4 . 3 9}$ \\
\hline
\end{tabular}

Experimental conditions: $V\left(\left[\mathrm{Bmim}_{3}\right] \mathrm{BF}_{4}\right)=5 \mathrm{~mL}, V\left(\mathrm{H}_{2} \mathrm{O}_{2}\right)=5 \mathrm{~mL}$, $m($ catalyst $)=0.5 \mathrm{~g}, m(\mathrm{HSPC})=0.5 \mathrm{~g}$

Bold values indicate the best sulfur removal by using a series of catalysts

The cyclic voltammetry (CV) results of CTAB @HPA$x(x=1-6)$ (Fig. 5) reveal that all samples can effectively reduce $\mathrm{OH}^{\cdot}$ and the reduction peak of the sample CTAB@ HPA- 5 centered at $-0.80 \mathrm{~V}$ has a higher positive potential, which is higher than that of CTAB @HPA- $x(x=1-4)$ and CTAB@HPA-6 ( -0.84 V). It reveals that CTAB@HPA-5 with better electrophilicity has better CODS performance, which is in well agreement with previous studies (Zhang et al. 2020; Ding et al. 2015; Wu et al. 2016). 


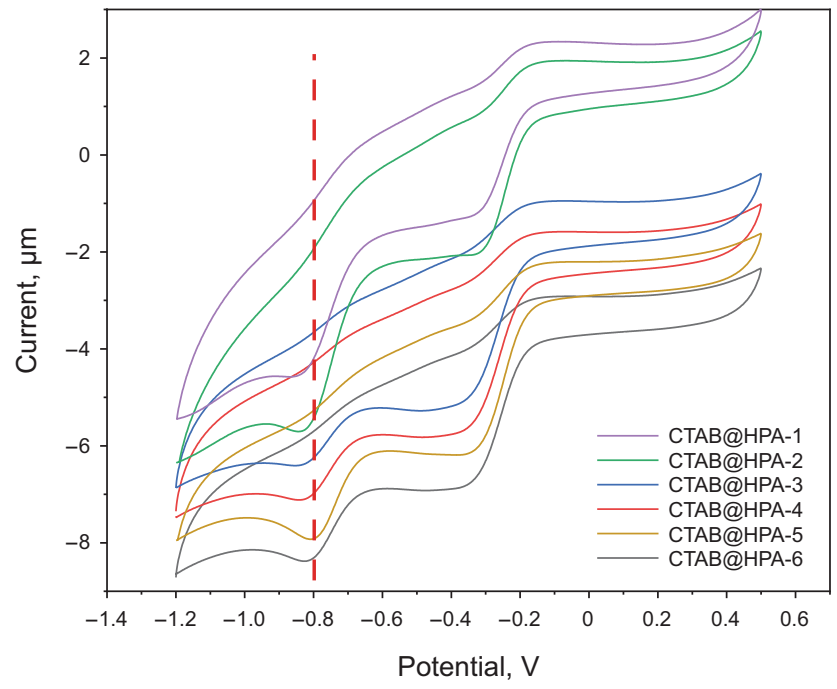

Fig. 5 CV curves of oxygen reduction reaction on CTAB@HPA- $x$ in $\mathrm{KOH}$ solutions $(0.1 \mathrm{M})$

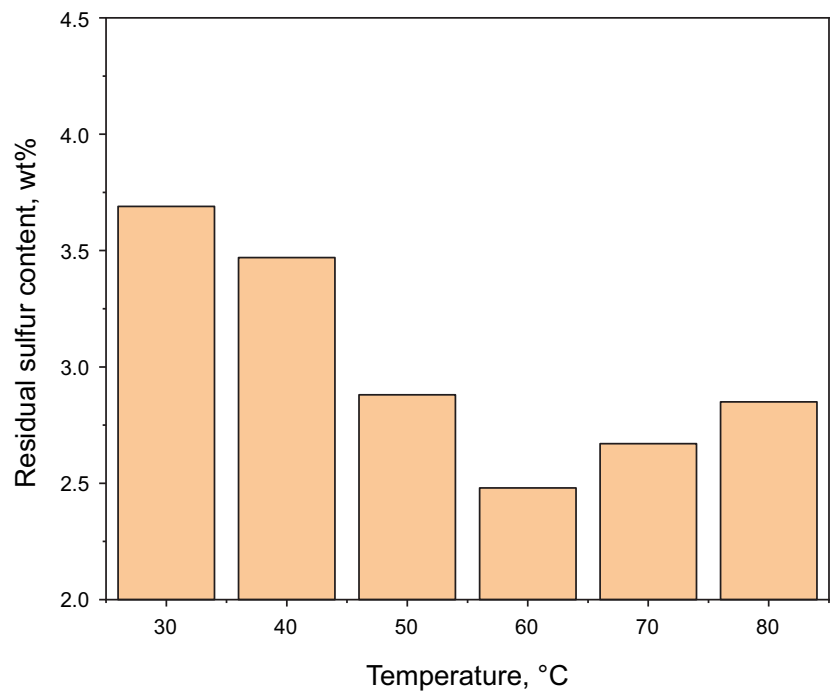

Fig. 6 Sulfur removal of HSPC with different reaction temperatures. Experimental conditions: $V\left(\left[\mathrm{Bmim}_{3} \mathrm{BF}_{4}\right)=5 \mathrm{~mL}, V\left(\mathrm{H}_{2} \mathrm{O}_{2}\right)=5 \mathrm{~mL}\right.$, $m(\mathrm{CTAB} @ \mathrm{HPA}-5)=0.5 \mathrm{~g}, m(\mathrm{HSPC})=0.5 \mathrm{~g}$

The effect of reaction temperature on the desulfurization performance of the representative CTAB@HPA-5 was further investigated. Figure 6 shows the residual sulfur content (wt \%) with different reaction temperatures on CTAB@HPA-5. Note that the sulfur removal distinctively increases with the increase in reaction temperatures from 30 to $60{ }^{\circ} \mathrm{C}$. When the reaction temperature is $30^{\circ} \mathrm{C}$, the residual sulfur content of petroleum coke is $3.69 \mathrm{wt} \%$. When the reaction temperature increase to $60{ }^{\circ} \mathrm{C}$, the residual sulfur content is $2.48 \mathrm{wt} \%$. It is generally accepted that the desulfurization reaction of HSPC is endothermic and that the increase in temperature is beneficial to the desulfurization process. However, the higher reaction temperature will result in the invalid decomposition of $\mathrm{H}_{2} \mathrm{O}_{2}$, thereafter reducing the utilization rate of $\mathrm{H}_{2} \mathrm{O}_{2}$, which matches well with the desulfurization result that further increasing the reaction temperature to $80^{\circ} \mathrm{C}$ inducing the dramatically increase in residual sulfur content. The above results demonstrate that the optimal reaction temperature for petroleum coke desulfurization is $60^{\circ} \mathrm{C}$.

It is known that sulfides in HSPC are mainly distributed in the interior of HSPC, and that some of them are attached to the carbon skeleton of HSPC and exposed on the surface of it. In order to get insight into the catalytic oxidation reaction kinetic of HSPC desulfurization on CTAB @HPA-5, we first recorded the desulfurization performance CTAB @ HPA-5 with the reaction time at $60{ }^{\circ} \mathrm{C}$. It can be observed in Fig. 6 a that the sulfur content sharply decreases with the increase in reaction time. When the reaction continues for $6 \mathrm{~h}$, the residual sulfur content in petroleum coke exhibits the lowest with $2.48 \mathrm{wt} \%$. Further extension of reaction time, the content of residual sulfur in petroleum coke remains unchanged.

According to the data presented in Fig. 7a, the relationship between $\ln \left(C_{0} / C_{t}\right)$ and reaction time was fitted. As shown in Fig. 7b. The kinetic equation is derived as follows (He et al. 2019; Zhang et al. 2013):

$-\mathrm{d} C_{t} / \mathrm{d} t=k C_{t}$

$\ln \left(C_{0} / \mathrm{C}_{t}\right)=k t$

$t_{1 / 2}=0.693 / k$

In the above equations, $k$ is the first-order reaction rate constant $\left(\mathrm{min}^{-1}\right)$, and $C_{0}$ and $C_{t}$ represent the sulfur content at time 0 and $t(\mathrm{~min})$, respectively. As shown in Fig. $7 \mathrm{~b}, \ln \left(C_{0} / C_{t}\right)$ shows a linear relationship with reaction time. It indicates that this catalytic oxidation process follows the first-order kinetic model.

To deeply understand the reaction process, the petroleum coke after reaction was collected and analyzed by a series of methods. Figure 8a shows that the intensities of characteristic peaks (744 and $863 \mathrm{~cm}^{-1}$ ) corresponding to thiophene are obviously weaker after reaction compared with the fresh sample. Moreover, the absorption peaks attributed to sulfone and sulfoxide appeared at 1083 and $1123 \mathrm{~cm}^{-1}$ instead. It reveals that the thiophene sulfur in HSPC is converted into sulfone and sulfoxide after catalytic oxidation reaction, and that some thiophene sulfur is oxidized to sulfate.

Figure $8 \mathrm{~b}$ shows the XRD patterns of petroleum coke after catalytic oxidation. The characteristic peaks (002) in 

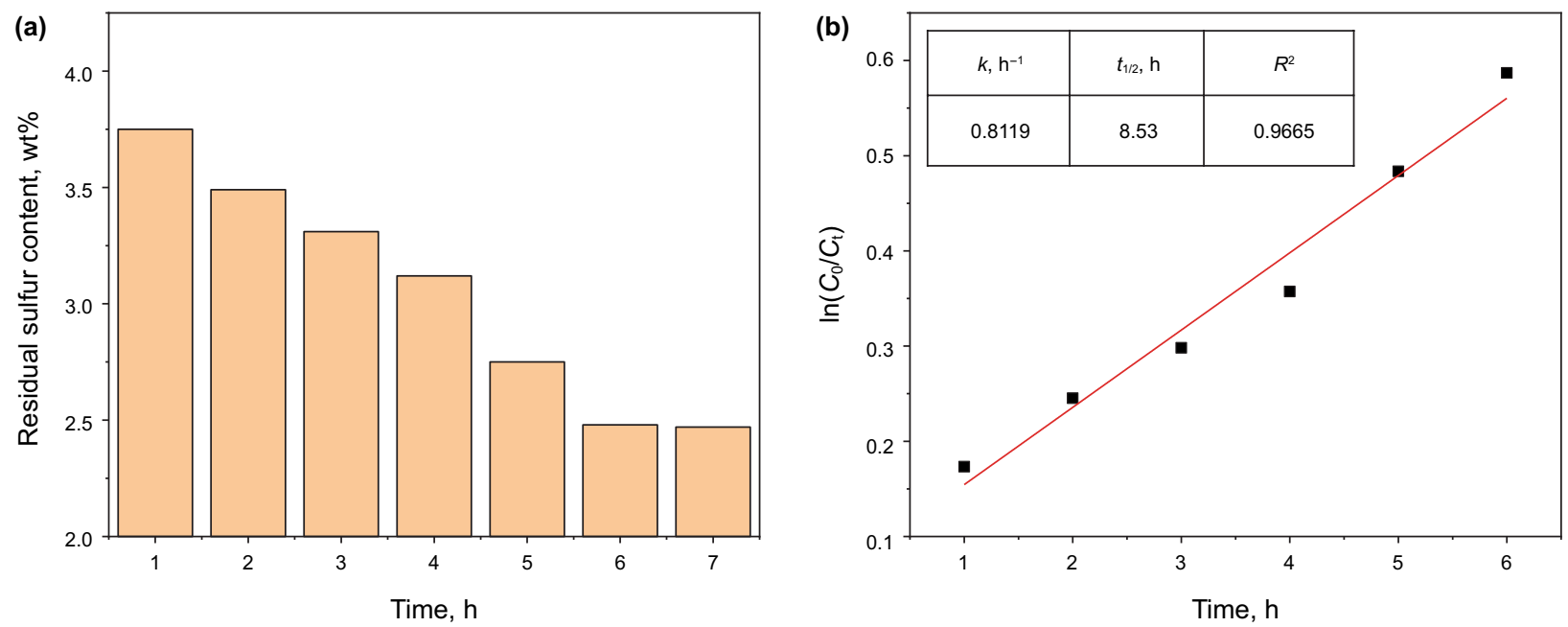

Fig. 7 a Sulfur removal of HSPC with different reaction time. b Catalytic oxidation reaction kinetics. Experimental conditions: $V([\mathrm{Bmim}]$ $\left.\mathrm{BF}_{4}\right)=5 \mathrm{~mL}, V\left(\mathrm{H}_{2} \mathrm{O}_{2}\right)=5 \mathrm{~mL}, T=60^{\circ} \mathrm{C}, m(\mathrm{CTAB} @ \mathrm{HPA}-5)=0.5 \mathrm{~g}, m(\mathrm{HSPC})=0.5 \mathrm{~g}$
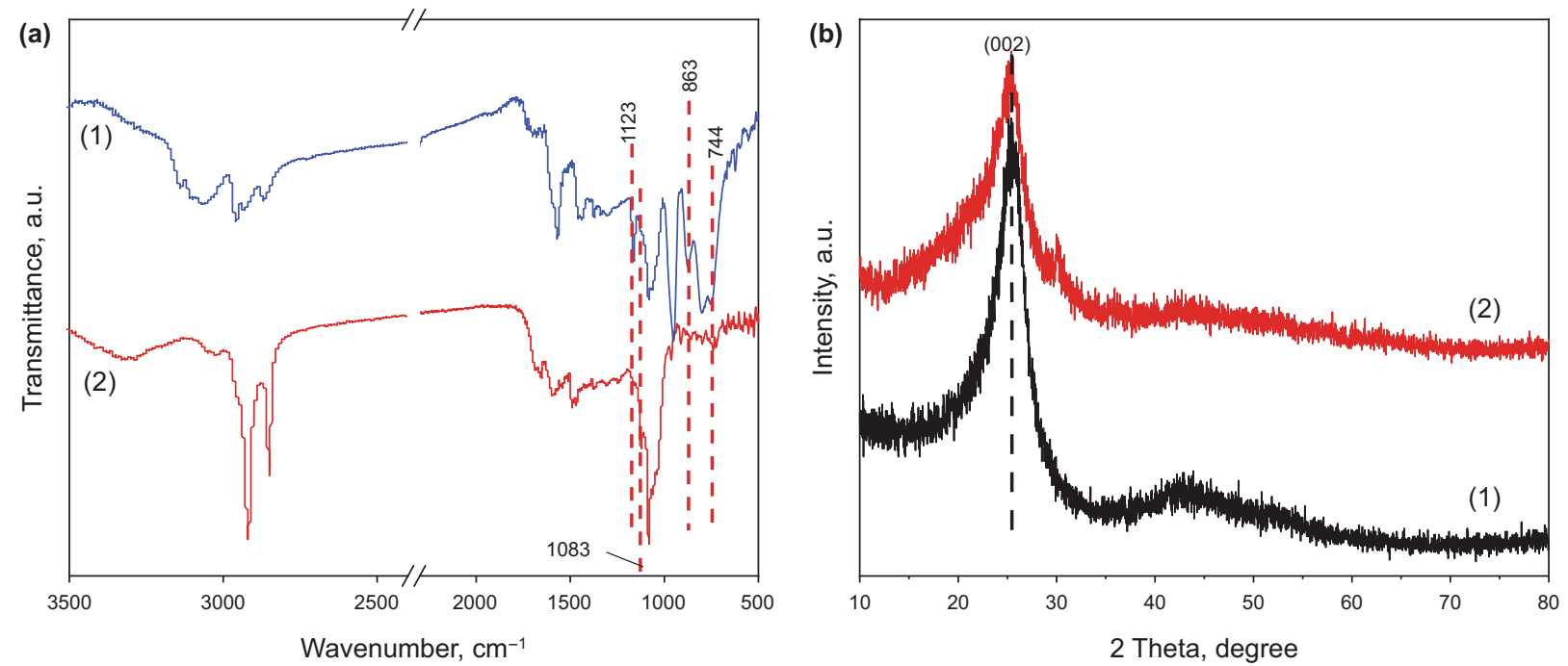

Fig. 8 (1) FT-IR and (2) XRD pattern. a: HSPC, b: petroleum coke treated by catalytic oxidative desulfurization

the patterns of the two samples are attributed to the petroleum coke crystal structure. It can be seen that the half width of the characteristic peaks corresponding to HSPC after oxidative desulfurization becomes wider than the fresh, and that the peak intensities decreased significantly. It unrevealed that the structure of amorphous carbon in petroleum coke after oxidative desulfurization is damaged, and the content is somewhat reduced. The above results demonstrate that the CTAB@HPA-5 catalyst introduced here can not only remove the sulfur from HSPC, but also reduce the carbon content (Fig. S1).

The surface sulfur elements in HSPC before and after desulfurization reaction were further investigated by XPS
(Fig. 9). As shown in Fig. 9d, the S 2p XPS of petroleum coke after catalytic oxidative desulfurization can be fitted to $163.2,164.2,164.8,166.1,167.2,168.7 \mathrm{eV}$, which are assigned to thiol, thiophene, disulfide, sulfoxide, sulfone and sulfate, respectively (Liu et al. 2020a). It reveals that the sulfides in the HSPC after reaction are mainly thiophene and thiol. In addition, the lone electron pair in the sulfur atom moves closer to the bonding electron pair, and the repulsion is greater, the electronegativity is stronger. This result indicates that thiophene and thiol parts will be removed as soluble salt over the CTAB @ HPA-5 catalyst with $\mathrm{H}_{2} \mathrm{O}_{2}$ as oxidant. 

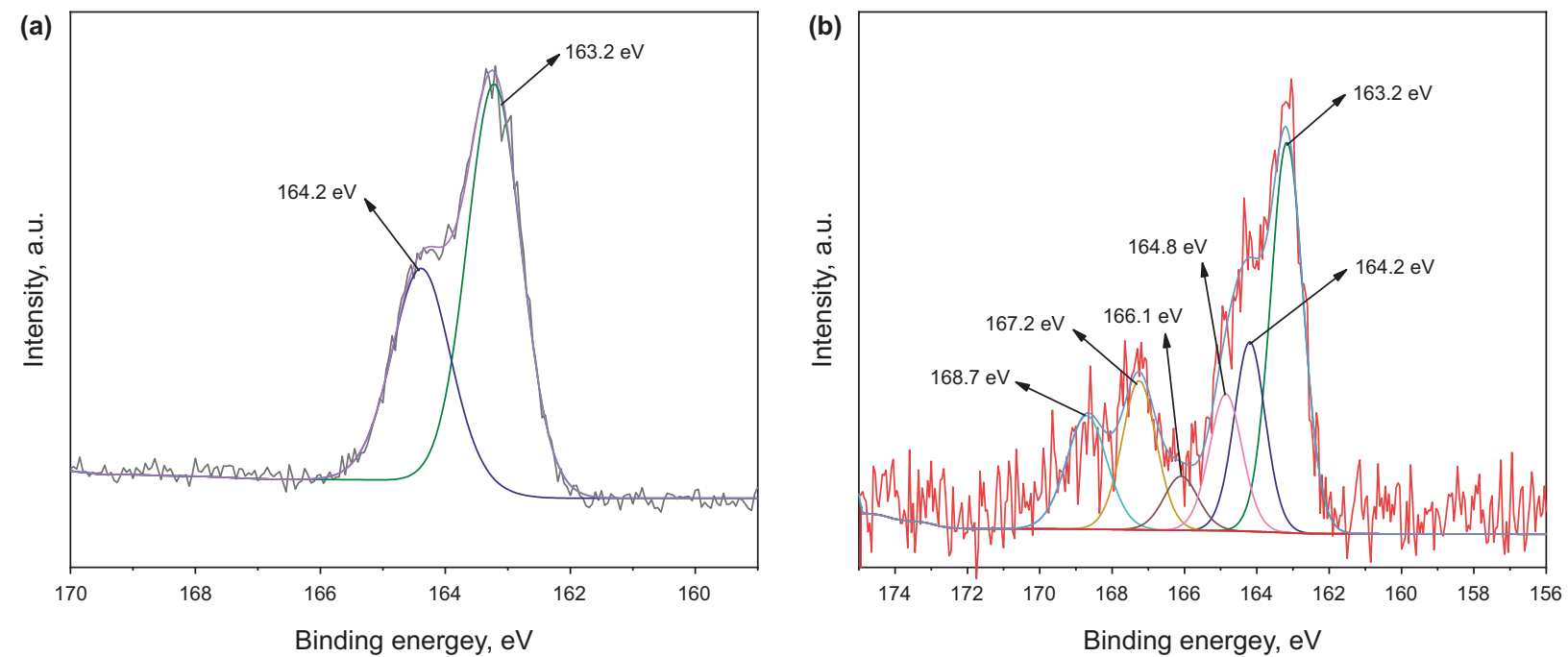

Fig. 9 XPS of a HSPC, b petroleum coke treated by catalytic oxidative desulfurization

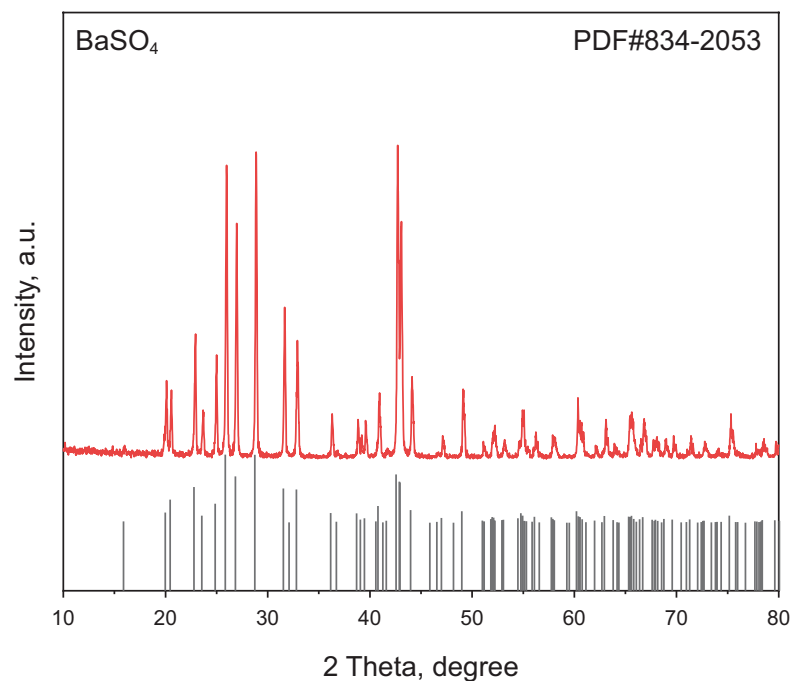

Fig. 10 XRD pattern of precipitation after catalytic oxidative desulfurization reaction

When the catalytic oxidative desulfurization reaction is completed, soluble barium salt is added to the filtrate to explore whether the catalytic oxidative desulfurization reaction produces $\mathrm{SO}_{4}{ }^{2-}$. After $\mathrm{Ba}^{2+}$ was introduced, the white precipitate was generated. Subsequently, the white precipitate was collected and analyzed by XRD, and the results are presented in Fig. 10. It can be clearly seen that the XRD pattern of the obtained precipitate coincides with the standard card (PDF\#834-2053), which is consistent with the XPS analyses.

In order to further probe the type of $\mathrm{H}_{2} \mathrm{O}_{2}$ played in this desulfurization process, we performed ESR experiments to confirm the type of free radicals generated during the

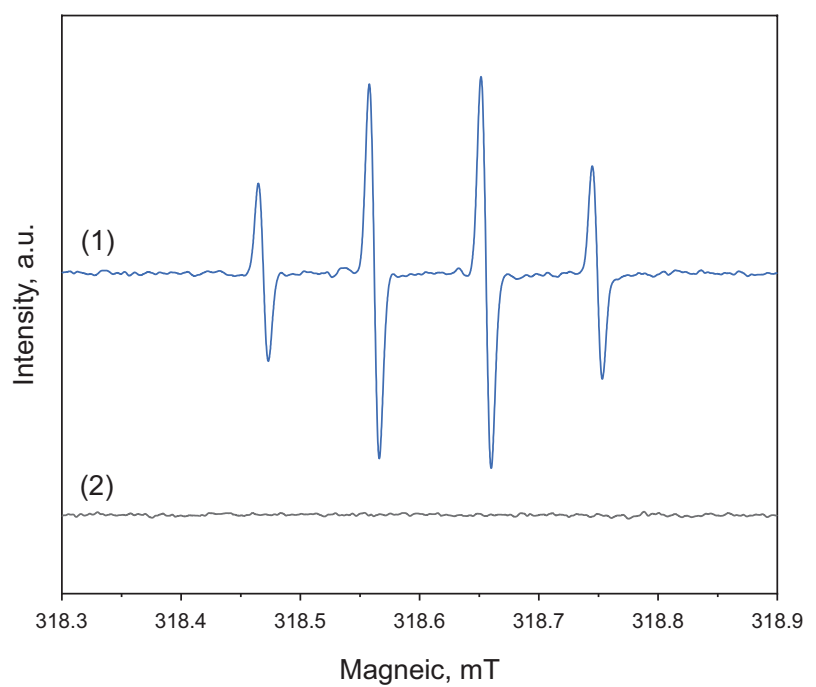

Fig. 11 ESR test of the catalytic oxidative desulfurization systems. a catalyst $+\mathrm{H}_{2} \mathrm{O}_{2}$, b $\mathrm{H}_{2} \mathrm{O}_{2}$

reaction, and the results are presented in Fig. 11. Here, 5.5-dimethyl-1-pyrroline- $\mathrm{N}$ oxide (DMPO) was invoked as a radical scavenger. After the introduction of CTAB@HPA5 , the characteristic peak assigned to DMPO-hydroxyl radical $(\mathrm{OH} \cdot)$ was detected. It indicates that $\mathrm{H}_{2} \mathrm{O}_{2}$ is activated by the catalyst to generate $\mathrm{OH}$, and then the $\mathrm{C}-\mathrm{S}$ bond is broken, and $\mathrm{S}$ and $\mathrm{O}$ are connected by covalent bonds to form a tetragonal pyramidal space structure and then lose two electrons to form a stable space structure to form sulfate radicals. Therefore, the desulfurization mechanism over CTAB@HPA-5 was proposed in Scheme 1; in the CTAB@ HPA-5 catalytic oxidation system, $\mathrm{W}$ plays a role as an electron donor, thereby transforming $\mathrm{V}^{5+}$ into a low valence 


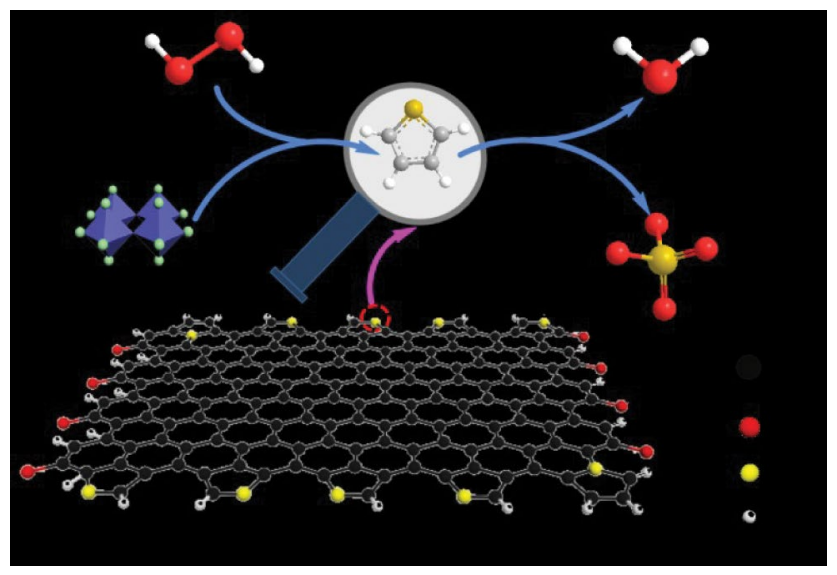

Scheme 1 Proposed mechanism for the catalytic oxidative desulfurization of petroleum coke

state (Liu et al. 2020d). Then, $\mathrm{V}^{4+}$ realizes $\mathrm{H}_{2} \mathrm{O}_{2}$ activation through a single electron transfer to form ${\mathrm{V}-\mathrm{O}^{-}}^{-}$active species, which will further oxidize to sulfate.

\section{Conclusions}

In summary, we design and construct a series of effective CTAB@HPA composites by a simple co-thermal method using CTAB and HPA as precursors, and the catalytic performances of the as-fabricated CTAB@HPA were investigated for the catalytic oxidation desulfurization of HSPC. It was found that the desulfurization activity of the catalytic was closely related to the vanadium content in heteropolyacids, and that CTAB@HPA-5 showed the highest desulfurization activity. After 6-h reaction at $60^{\circ} \mathrm{C}$, the sulfur content in HSPC decreased to $2.48 \mathrm{wt} \%$. FT-IR, XRD and XPS showed that $\mathrm{H}_{2} \mathrm{O}_{2}$ could oxidize sulfide in HSPC to sulfone, sulfoxide and sulfate. This paper not only realizes the waste reuse of HSPC, but also provides an effective design idea for the desulfurization of HSPC.

\section{Supporting information}

Experimental details and additional data, synthesis data from different amounts of vanadium substituted HPA- $x$ catalyst in this article. BET analysis of the HSPC desulfurization performance, SEM analysis of the morphology of HSPC before and after desulfurization. All the applied characterizations for catalyst samples.

Supplementary information The online version of this article (https:// doi.org/10.1007/s12182-021-00553-2).
Acknowledgements This work was financially supported by the National Natural Science Foundation of China (No. 21722604), the Postdoctoral Foundation of China (Nos. 2019M651743 and 2020M671365), the Natural Science Foundation of Jiangsu Province (No. BK20190852), the National Youth Natural Science Foundation (No. 8111310009).

Open Access This article is licensed under a Creative Commons Attribution 4.0 International License, which permits use, sharing, adaptation, distribution and reproduction in any medium or format, as long as you give appropriate credit to the original author(s) and the source, provide a link to the Creative Commons licence, and indicate if changes were made. The images or other third party material in this article are included in the article's Creative Commons licence, unless indicated otherwise in a credit line to the material. If material is not included in the article's Creative Commons licence and your intended use is not permitted by statutory regulation or exceeds the permitted use, you will need to obtain permission directly from the copyright holder. To view a copy of this licence, visit http://creativecommons.org/licenses/by/4.0/.

\section{References}

Agarwal P, Sharma DK. Studies on the desulfurization of petroleum coke by organorefining and other chemical and biochemical techniques under milder ambient pressure conditions. Pet Sci Technol. 2011;29(14):1482-93. https://doi.org/10.1080/109164609028392 30.

Banisharif F, Dehghani MR, Campos-Martin JM. Oxidative desulfurization of diesel using vanadium-substituted dawson-type emulsion catalysts. Energy Fuels. 2017;31(5):5419-27. https://doi. org/10.1021/acs.energyfuels.6b02791.

Bertleff B, Claußnitzer J, Korth W, Wasserscheid P, Jess A, Albert J. Extraction coupled oxidative desulfurization of fuels to sulfate and water-soluble sulfur compounds using polyoxometalate catalysts and molecular oxygen. ACS Sustain Chem Eng. 2017;5(5):4110 8. https://doi.org/10.1021/acssuschemeng.7b00087.

Briceño S, Silva P, Molina W, Brämer-Escamilla W, Alcalá O, Cañizales E. Magnetic properties of $\mathrm{NiFe}_{2} \mathrm{O}_{4} /$ carbon nanofibers from Venezuelan petcoke. J Magn Magn Mater. 2015;381:10-3. https ://doi.org/10.1016/j.jmmm.2014.12.034.

Chen J, Lu X. Progress of petroleum coke combusting in circulating fluidized bed boilers-A review and future perspectives. Resour Conserv Recycl. 2007;49(3):203-16. https://doi.org/10.1016/j. resconrec.2006.03.012.

Chen Z, Wei K, Wu J, Li S, Zhang C, Yu Z, et al. Detailed vacuumassisted desulfurization of high-sulfur petroleum coke $[\mathrm{J}]$. Sep Purif Technol Sep Purif Technol. 2017;175:7. https://doi. org/10.1016/j.seppur.2016.11.035.

Chen Q, Li W, Ling K, Yang R. Effect of $\mathrm{Na}_{2} \mathrm{WO}_{4}$ addition on formation mechanism and microstructure of micro-arc oxidation coating on Al-Ti double-layer composite plate. Mater Des. 2020;190:108558. https://doi.org/10.1016/j.matdes.2020.108558.

Chi M, Su T, Sun L, Zhu Z, Liao W, Ren W, et al. Biomimetic oxygen activation and electron transfer mechanism for oxidative desulfurization. Appl Catal B Environ. 2020;275:119134. https://doi. org/10.1016/j.apcatb.2020.119134.

Choi J, Barnard ZG, Zhang S, Hill JM. Ni catalysts supported on activated carbon from petcoke and their activity for toluene hydrogenation. Can J Chem Eng. 2012;90(3):631-6. https://doi. org/10.1002/cjce.20545.

Dablemont C, Hamaker CG, Thouvenot R, Sojka Z, Che M, Maatta EA, et al. Functionalization of heteropolyanions-osmium and rhenium nitrido derivatives of Keggin-type and Dawson-type 
polyoxotungstates: synthesis, characterization and multinuclear ((183)W, (15)N) NMR, EPR, IR, and UV/Vis fingerprints. Chem. 2006;12(36):9150-60. https://doi.org/10.1002/chem.200600934.

Ding W, Zhu W, Xiong J, Yang L, Wei A, Zhang M, et al. Novel heterogeneous iron-based redox ionic liquid supported on SBA15 for deep oxidative desulfurization of fuels. Chem Eng J. 2015;266:213-21. https://doi.org/10.1016/j.cej.2014.12.040.

Ganiyu SA, Alhooshani K, Ali SA. Single-pot synthesis of Ti-SBA15-NiMo hydrodesulfurization catalysts: role of calcination temperature on dispersion and activity. Appl Catal B Environ. 2017;203:428-41. https://doi.org/10.1016/j.apcatb.2016.10.052.

Gim MY, Choi JH, Kang TH, Song IK. Redox properties of nanostructured alpha(2)- $\mathrm{K}_{6} \mathrm{As}_{2} \mathrm{~W}_{18-x} \mathrm{Mo}_{x} \mathrm{O}_{62}(x=0-3)$ Wells-Dawson heteropolyacid catalysts probed by scanning tunneling microscopy. J Nanosci Nanotechnol. 2016;16(10):10823-8. https://doi. org/10.1166/jnn.2016.13247.

Han C, Duan X, Zhang M, Fu W, Duan X, Ma W, et al. Role of electronic properties in partition of radical and nonradical processes of carbocatalysis toward peroxymonosulfate activation. Carbon. 2019;153:73-80. https://doi.org/10.1016/j.carbon.2019.06.107.

Hao L, Sun L, Su T, Hao D, Liao W, Deng C, et al. Polyoxometalate-based ionic liquid catalyst with unprecedented activity and selectivity for oxidative desulfurization of diesel in [Omim] $\mathrm{BF}_{4}$. Chem Eng J. 2019;358:419-26. https://doi.org/10.1016/j. cej.2018.10.006.

He J, Wu P, Lu L, Sun H, Jia Q, Hua M, et al. Synthesis of N, O-Doped porous graphene from petroleum coke for deep oxidative desulfurization of fuel. Energy Fuels. 2019;33(9):8302-11. https://doi. org/10.1021/acs.energyfuels.9b01832.

Ishihara A, Wang D, Dumeignil F, Amano H, Qian EW, Kabe T. Oxidative desulfurization and denitrogenation of a light gas oil using an oxidation/adsorption continuous flow process. Appl Catal A Gen. 2005;279(1-2):279-87. https://doi.org/10.1016/j.apcat a.2004.10.037.

Jiang W, Jia H, Zheng Z, Zhu L, Dong L, Liu W, et al. Catalytic oxidative desulfurization of fuels in acidic deep eutectic solvents with $\left[\left(\mathrm{C}_{6} \mathrm{H}_{13}\right)_{3} \mathrm{P}\left(\mathrm{C}_{14} \mathrm{H}_{29}\right)\right]_{3} \mathrm{PMo}_{12} \mathrm{O}_{40}$ as a catalyst. Pet Sci. 2018;15(4):841-8. https://doi.org/10.1007/s12182-018-0263-9.

Li M, Zhang M, Wei A, Zhu W, Xun S, Li Y, et al. Facile synthesis of amphiphilic polyoxometalate-based ionic liquid supported silica induced efficient performance in oxidative desulfurization. J Mol Catal A Chem. 2015;406:23-30. https://doi.org/10.1016/j.molca ta.2015.05.007.

Li T, Li J, Zhang H, Sun K, Xiao J. DFT research on benzothiophene pyrolysis reaction mechanism. J Phys Chem A. 2019a;123(4):796810. https://doi.org/10.1021/acs.jpca.8b09882.

Li Z, Cui Y, Li C, Shen Y. Deep desulfurization of fuels based on deep eutectic theory. Sep Purif Technol. 2019b;219:9-15. https://doi. org/10.1016/j.seppur.2019.03.003.

Li S, Li Y, Jin M, Miao K, Gu M, Liu X, et al. Controllable fabrication of cuprous sites in confined spaces for efficient adsorptive desulfurization. Fuel. 2020;259:116221. https://doi.org/10.1016/j. fuel.2019.116221.

Liu H, Xu H, Hua M, Chen L, Wei Y, Wang C, et al. Extraction combined catalytic oxidation desulfurization of petcoke in ionic liquid under mild conditions. Fuel. 2020a;260:116200. https://doi. org/10.1016/j.fuel.2019.116200.

Liu J, Cheng H, Tan J, Liu B, Zhang Z, Xu H, et al. Solvent-free rapid synthesis of porous $\mathrm{CeWO}_{x}$ by a mechanochemical selfassembly strategy for the abatement of $\mathrm{NO}_{x}$. J Mater Chem A. 2020b;8(14):6717-31. https://doi.org/10.1039/d0ta01541e.

Liu J, Wang L, Okejiri F, Luo J, Zhao J, Zhang P, et al. Deep understanding of strong metal interface confinement: a journey of $\mathrm{Pd} /$ $\mathrm{FeO}_{x}$ catalysts. ACS Catal. 2020c;10(15):8950-9. https://doi. org/10.1021/acscatal.0c01447.
Liu Y, Han L, Zhang J, Yao R, Zhan H, Yang H, et al. Morphology-controlled construction and aerobic oxidative desulfurization of hierarchical hollow $\mathrm{Co}-\mathrm{Ni}-\mathrm{Mo}-\mathrm{O}$ mixed metal-oxide nanotubes. Ind Eng Chem Res. 2020d;59(14):6488-96. https://doi.org/10.1021/ acs.iecr.9b06988.

Long DL, Tsunashima R, Cronin L. Polyoxometalates: building blocks for functional nanoscale systems. Angew Chem Int Ed. 2010;49(10):1736-58. https://doi.org/10.1002/anie.200902483.

Lu L, He J, Wu P, Wu Y, Chao Y, Li H, et al. Taming electronic properties of boron nitride nanosheets as metal-free catalysts for aerobic oxidative desulfurization of fuels. Green Chem. 2018;20(19):4453-60. https://doi.org/10.1039/c8gc01625a.

Muñoz M, Gallo MA, Gutiérrez-Alejandre A, Gazzoli D, Cabello CI. Molybdenum-containing systems based on natural kaolinite as catalysts for selective oxidation of aromatic sulfides. Appl Catal B Environ. 2017;219:683-92. https://doi.org/10.1016/j.apcat b.2017.08.007.

Peng H, Zhang J, Zhang J, Zhong F, Wu P, Huang K, et al. Chitosanderived mesoporous carbon with ultrahigh pore volume for amine impregnation and highly efficient $\mathrm{CO}_{2}$ capture. Chem Eng J. 2019;359:1159-65. https://doi.org/10.1016/j.cej.2018.11.064.

Rohani N, Bamoharram FF, Marjani A, Heravi MM. Gold nanoparticles Wells-Dawson heteropolyacid nanocomposite film as an effective nanocatalyst in photocatalytic removal of azo dyes from wastewaters. J Nanostruct Chem. 2017;7(2):171-8. https://doi. org/10.1007/s40097-017-0218-5.

Song J, Li Y, Cao P, Jing X, Faheem M, Matsuo Y, et al. Synergic catalysts of polyoxometalate@ cationic porous aromatic frameworks: reciprocal modulation of both capture and conversion materials. Adv Mater. 2019;31(40):e1902444. https://doi.org/10.1002/ adma.201902444.

Te M, Fairbridge C, Ring Z. Oxidation reactivities of dibenzothiophenes in polyoxometalate $/ \mathrm{H}_{2} \mathrm{O}_{2}$ and formic acid/ $\mathrm{H}_{2} \mathrm{O}_{2}$ systems. Appl Catal A General. 2001;219(1-2):267-80. https://doi. org/10.1016/s0926-860x(01)00699-8.

Toledo-Antonio JA, Cortes-Jacome MA, Escobar-Aguilar J, AngelesChavez C, Navarrete-Bolaños J, López-Salinas E. Upgrading HDS activity of $\mathrm{MoS}_{2}$ catalysts by chelating thioglycolic acid to MoOx supported on alumina. Appl Catal B Environ. 2017;213:106-17. https://doi.org/10.1016/j.apcatb.2017.05.011.

Wang C, Bu X, Ma J, Liu C, Chou K, Wang X, et al. Wells-Dawson type $\mathrm{Cs}_{5.5} \mathrm{H}_{0.5} \mathrm{P}_{2} \mathrm{~W}_{18} \mathrm{O}_{62}$ based $\mathrm{Co} / \mathrm{Al}_{2} \mathrm{O}_{3}$ as bifunctional catalysts for direct production of clean-gasoline fuel through FischerTropsch synthesis. Catal Today. 2016;274:82-7. https://doi. org/10.1016/j.cattod.2016.01.043.

Wang C, Yi Y, Li H, Wu P, Li M, Jiang W, et al. Rapid gas-assisted exfoliation promises $\mathrm{V}_{2} \mathrm{O}_{5}$ nanosheets for high performance lithium-sulfur batteries. Nano Energy. 2020;67:104253. https://doi. org/10.1016/j.nanoen.2019.104253.

Wei J, Guo Q, Ding L, Yoshikawa K, Yu G. Synergy mechanism analysis of petroleum coke and municipal solid waste (MSW)-derived hydrochar co-gasification. Appl Energy. 2017;206:1354-63. https ://doi.org/10.1016/j.apenergy.2017.10.005.

Wu P, Zhu W, Dai B, Chao Y, Li C, Li H, et al. Copper nanoparticles advance electron mobility of graphene-like boron nitride for enhanced aerobic oxidative desulfurization. Chem Eng J. 2016;301:123-31. https://doi.org/10.1016/j.cej.2016.04.103.

Wu M, Liu Y, Zhu Y, Lin J, Liu J, Hu H, et al. Supramolecular polymerization-assisted synthesis of nitrogen and sulfur dual-doped porous graphene networks from petroleum coke as efficient metal-free electrocatalysts for the oxygen reduction reaction. J Mater Chem A. 2017;5(22):11331-9. https://doi.org/10.1039/ c7ta03264a.

Xiao J, Huang J, Zhong Q, Li F, Zhang H, Li J. A real-time mathematical model for the two-dimensional temperature field of petroleum 
coke calcination in vertical shaft calciner. Jom. 2016;68(8):214959. https://doi.org/10.1007/s11837-016-1846-9.

Yang H, Jiang B, Sun Y, Zhang L, Sun Z, Wang J, et al. Polymeric cation and isopolyanion ionic self-assembly: novel thin-layer mesoporous catalyst for oxidative desulfurization. Chem Eng J. 2017;317:32-41. https://doi.org/10.1016/j.cej.2017.01.135.

Yao X, Wang C, Liu H, Li H, Wu P, Fan L, et al. Immobilizing highly catalytically molybdenum oxide nanoparticles on graphene-analogous bn: stable heterogeneous catalysts with enhanced aerobic oxidative desulfurization performance. Ind Eng Chem Res. 2018;58(2):863-71. https://doi.org/10.1021/acs.iecr.8b05088.

Zhang M, Zhu W, Xun S, Li H, Gu Q, Zhao Z, et al. Deep oxidative desulfurization of dibenzothiophene with POM-based hybrid materials in ionic liquids. Chem Eng J. 2013;220:328-36. https ://doi.org/10.1016/j.cej.2012.11.138.

Zhang M, Wei Y, Li R, Zhu W, Li H, Zhang Q, et al. Magnetic POMbased mesoporous silica for fast oxidation of aromatic sulfur compounds. Fuel. 2017;209:545-51. https://doi.org/10.1016/j. fuel.2017.08.001.

Zhang M, Liu J, Li H, Wei Y, Fu Y, Liao W, et al. Tuning the electrophilicity of vanadium-substituted polyoxometalate based ionic liquids for high-efficiency aerobic oxidative desulfurization. Appl Catal B Environ. 2020;271:118936. https://doi.org/10.1016/j. apcatb.2020.118936.
Zhao P, Ma C, Wang J, Qiao W, Ling L. Almost total desulfurization of high-sulfur petroleum coke by $\mathrm{Na}_{2} \mathrm{CO}_{3}$-promoted calcination combined with ultrasonic-assisted chemical oxidation. New Carbon Mater. 2018;33(6):587-94. https://doi.org/10.1016/s1872 $-5805(18) 60359-2$.

Zhong Q, Mao Q, Xiao J, van Duin A, Mathews JP. Sulfur removal from petroleum coke during high-temperature pyrolysis. Analysis from TG-MS data and ReaxFF simulations. J Anal Appl Pyrol. 2018a;132:134-42. https://doi.org/10.1016/j.jaap.2018.03.007.

Zhong Q, Xiao J, van Duin ACT, Mathews JP. ReaxFF simulations of petroleum coke sulfur removal mechanisms during pyrolysis and combustion. Combust Flame. 2018b;198:148-57. https://doi. org/10.1016/j.combustflame.2018.09.005.

Zhong Q, Zhang Y, Shabnam S, Mao Q, Xiao J, van Duin ACT, et al. ReaxFF MD simulations of petroleum coke $\mathrm{CO}_{2}$ gasification examining the $\mathrm{S} / \mathrm{N}$ removal mechanisms and $\mathrm{CO} / \mathrm{CO}_{2}$ reactivity. Fuel. 2019;257:116051. https://doi.org/10.1016/j.fuel.2019.11605 1.

Zhu W, Gao X, Li Q, Li H, Chao Y, Li M, et al. Controlled gas exfoliation of boron nitride into few-layered nanosheets. Angew Chem Int Ed. 2016;55(36):10766-70. https://doi.org/10.1002/anie.20160 5515. 